\title{
Seed Transmission of Wheat streak mosaic virus Shown Unequivocally in Wheat
}

\author{
Roger A. C. Jones, Brenda A. Coutts, and Alison E. Mackie, Plant Pathology Section, Department of Agriculture, \\ Locked Bag No. 4, Bentley Delivery Centre, WA 6983, Australia, and Geoffrey I. Dwyer, Saturn Biotech Ltd., State \\ Agricultural Biotechnology Centre, Murdoch University, WA 6150, Australia
}

\begin{abstract}
Jones, R. A. C., Coutts, B. A., Mackie, A. E., and Dwyer, G. I. 2005. Seed transmission of Wheat streak mosaic virus shown unequivocally in wheat. Plant Dis. 89:1048-1050.

Under conditions that excluded any possibility of eriophyid mite vector activity, seed transmission of Wheat streak mosaic virus (WSMV) was shown in eight different wheat genotypes at rates of 0.5 to $1.5 \%$. Virus identification in seedlings came from characteristic symptoms in wheat, enzyme-linked immunosorbent assay with WSMV-specific antibodies, reverse-transcription polymerase chain reaction tests with WSMV-specific primers, and cDNA sequence comparisons with published sequences. Sequence comparisons of four seedborne isolates showed $\geq 98.6 \%$ identity with the eight Australian isolates in GenBank, indicating a common seedborne origin of WSMV. These findings warrant reconsideration of currently accepted views on WSMV epidemiology and the likelihood of introducing it to new locations through planting untested wheat seed and the movement of germplasm.
\end{abstract}

Additional keywords: epidemics, quarantine, reservoirs

Wheat streak mosaic virus (WSMV; genus Tritimovirus, family Potyviridae) infects wheat in parts of North America, Europe, the Middle East, North Africa, and Central, East, and Southeast Asia. It is an especially serious pathogen in the Great Plains region of North America. Annual WSMV-induced yield losses are about 5\% in this region, although local outbreaks can be very destructive, causing yield losses approaching $100 \%(2,6)$. WSMV is transmitted from plant to plant by the wheat leaf curl mite (Aceria tosichella) (5). Infected volunteer cereals and grasses surviving outside the wheat growing season constitute reservoirs from which WSMV and its eriophyid mite vector spread to wheat crops (13). However, widespread WSMV epidemics still occur unpredictably when such WSMV reservoirs are absent (6). Hill et al. (8) reported seed transmission of WSMV at $0.1 \%$ in maize, but conclusive proof was not obtained because the virus was detected in only one seedling and there were no precautions to ensure freedom from vector mites. Because the mite vector is tiny enough to pass through holes in standard aphid-proof mesh used in glasshouses, it can enter them

Corresponding author: R. A. C. Jones

E-mail: rjones@agric.wa.gov.au

Nucleotide sequences reported in this paper will appear in the GenBank database under accession numbers AY85846, AY85847, AY85848 and AY85849.

Accepted for publication 24 May 2005.

DOI: 10.1094/PD-89-1048

(C) 2005 The American Phytopathological Society and, if viruliferous, infect seedlings before they are virus tested.

In 2002, WSMV was identified infecting wheat and pasture grasses in eastern Australia $(3,4)$. In the same year, the Western Australian Department of Agriculture undertook a wide-scale, out-of-growingseason survey of potential perennial grass and volunteer cereal hosts. For this, 10,862 leaf samples were collected from diverse locations in the extensive "wheatbelt" region of the state, and 4,962 samples were collected from glasshouses and irrigated plot areas on five research institutes in Perth city. No WSMV was detected (unpublished data). In 2004, seed of 300 different wheat genotypes from an International Maize and Wheat Improvement Center (CIMMYT) breeding collection were sown in a quarantine glasshouse in Perth. This collection was propagated previously in an irrigated breeding nursery area in Queensland, Australia with a known recent history of WSMV infection. Some of the seedlings developed symptoms of leaf mosaic, streaking and distortion, and plant stunting. These symptoms were suggestive of seedborne viral infection because all foliage was symptomatic. When tested with WSMV-specific antibodies, the virus was detected in leaf samples from the symptomatic plants. This article reports an investigation to determine whether WSMV is seedborne in wheat under conditions that exclude any possibility of its mite vector being able to infect seedlings before they are tested.

MATERIALS AND METHODS

Seed source and virus culture. The CIMMYT nursery collection contained
300 different wheat genotypes propagated previously at the Leslie Research Centre in Toowoomba, Queensland, Australia. WSMV isolate 'Canberra' (accession no. AY327865) was obtained from CSIRO, Canberra, Australia. It was maintained by sap inoculation in wheat cv. Spear and kept at approximately $20^{\circ} \mathrm{C}$ in an isolated controlled environment cabinet. This culture was used as a positive control in enzymelinked immunosorbent assay (ELISA) and reverse-transcription polymerase chain reaction (RT-PCR) tests, and healthy wheat cv. Spear provided a negative control.

Survey for alternative WSMV sources. A range of potential WSMV hosts were sampled from within and around the quarantine glasshouse. These comprised (i) 360 wheat and 10 bamboo (Bambusa vulgaris) samples, the only other hosts growing inside the glasshouse; (ii) 200 grass weeds growing around the glasshouse, consisting of different numbers of samples of wild oat (Avena sp.), silvergrass (Vulpia $\mathrm{sp}$.), annual rygegrass (Lolium rigidum), couch grass (Cynodon dactylon), lesser Canary grass (Phalaris minor), African lovegrass (Eragrostis curvula), and crabgrass (Digitaria sanguinalis); and (iii) 350 barley, 950 wheat, and 100 oat samples collected at random from 16 nearby irrigated plots. One leaf sample was taken per plant and these samples were combined in groups of 10 for ELISA tests.

Virus detection in samples and sequence analysis. For ELISA, leaf material was extracted and tested as described previously (10) using WSMV-specific antibodies (Loewe Biochemica, Sauerlach, Germany). The only modification was a blocking step involving the addition of skim milk powder to the conjugate buffer to give a concentration of $25 \mathrm{~g} /$ liter. Absorbance values (absorbance at $405 \mathrm{~nm}$ [ $\left.\left.A_{405 \mathrm{~nm}}\right]\right)$ from positive tests on wheat samples always were more than five times those of the negative tests on healthy wheat leaf samples. Percentage of seed transmission was calculated from grouped sample test results using the formula of Gibbs and Gower (7). To extract RNA, leaf material was ground to a fine powder in liquid nitrogen and total RNA extracted with an RNAeasy Plant Mini kit according to the manufacturer's instructions (Qiagen, Doncaster, Victoria, Australia). The primers used to anneal to the WSMV coat protein gene (SB103, 5'GATCAAATACCAACCGCGTG, and SB106, 5'GTGACGCATAATGGCTCGAAG; SB104, 5'GGG- 
CTTGATGTRACAGAGG, and SB105, 5'TCACATCATCTGCATCATGACGTG) amplified 290- and 493-bp fragments, respectively. In the initial test, two primer sets were used to confirm that WSMV was being amplified. Primers SB103 and SB106 also amplify a nonspecific fragment from wheat; therefore, only primers SB104 and SB105 were used in the two seed transmission experiments. RT-PCR was done using the GeneAmp RNA PCR kit according to the manufacturer's instructions (Applied Biosystem, Scoresby, Victoria, Australia). The RT reaction was done in a final volume of $10 \mu \mathrm{l}$ containing 10 pmol of reverse primer (SB105 or SB106) and $1 \mu \mathrm{l}$ of RNA extract, and the reaction was incubated at $42^{\circ} \mathrm{C}$ for $30 \mathrm{~min}$, followed by $96^{\circ} \mathrm{C}$ for $5 \mathrm{~min}$. For PCR, the reaction was increased to a final volume of $50 \mu \mathrm{l}$ with the addition of 10 pmol of forward primer (SB103 or SB104). PCR cycling involved initial denaturation at $94^{\circ} \mathrm{C}$ for $3 \mathrm{~min}$; followed by 30 cycles of $94^{\circ} \mathrm{C}$ for $30 \mathrm{~s}, 55^{\circ} \mathrm{C}$ for $30 \mathrm{~s}$, and $72^{\circ} \mathrm{C}$ for $60 \mathrm{~s}$; with a final extension at $72^{\circ} \mathrm{C}$ for $7 \mathrm{~min}$. PCR products were sequenced directly from both strands and compared with published GenBank entries using Blastn (National Center for Biotechnology Information [NCBI], Bethesda, MD; 1).

Virus identification and seed transmission experiments. In the initial test, one leaf per seedling was collected from 926 4-week-old wheat seedlings from the CIMMYT collection growing in the quarantine glasshouse. These were divided into groups each consisting of leaves from three genotypes, and samples from each group combined in batches of 7 to 12 leaves for testing by ELISA. Grouped samples that were positive were retested by RT-PCR, and a PCR product from each primer pair was sequenced. The leaves from positive grouped samples then were retested individually by ELISA. Two seed transmission experiments were performed. In experiment 1 , seed from 25 different genotypes was surface sterilized by immersion in $1.25 \%$ bleach for $30 \mathrm{~s}$. The seed was rolled in moist paper towels, and the towels then placed immediately afterward in sealed plastic bags and incubated at $22^{\circ} \mathrm{C}$ to germinate (11). All laboratory surfaces were washed down daily with $70 \%$ ethanol. After 6 days, the top portion of the first leaf only was sampled from each germinated seedling, the samples grouped in 10 s within individual genotypes, and the grouped samples tested by ELISA. In experiment 2, seed from 18 different genotypes was germinated in the same way but the ELISA tests were done after 12 days. Positive and negative grouped samples (three each) then were retested by RT-PCR and the PCR products sequenced.

\section{RESULTS}

In the initial test, 4 of 86 grouped leaf samples tested positive for WSMV by
ELISA and the presence of WSMV in these 4 was confirmed by RT-PCR. When the leaves from the positive groups were retested individually by ELISA, five were positive and these belonged to the CIMMYT genotypes 1ISWSN5, 20SAWSN88, 21SAWSN59, 21SAWSN63, and 21SAWSN85. The overall seed transmission rate for WSMV was $0.5 \%$. When plants of these five genotypes growing in the quarantine glasshouse were inspected, the infected ones exhibited typical symptoms of WSMV consisting of leaf mosaic, streaking and distortion, and plant stunting. No positive results were obtained in any ELISA tests on samples of other wheat material or bamboo from within the quarantine glasshouse, grass weeds collected from around the glasshouse, or cereals from the adjacent irrigated area. Also, none of the original plants these samples came from were symptomatic. Sequence analysis of the combined RT-PCR products (582 bp) for isolate SP-1 (accession no. AY85846) from genotype 1ISWSN5 showed that it shared 82.0 to $99.8 \%$ identity with published WSMV sequences. Of these, 8 of the top 11 Blastn matches were with Australian isolates ( $\geq 98.6 \%)$, the best match being $99.83 \%$ with the 'Bordertown' isolate (accession no. AY327870).

In seed transmission experiment 1 , grouped samples belonging to 5 of 25 different genotypes gave positive results for WSMV in ELISA, giving an overall seed transmission rate of $0.2 \%$ (Table 1). The seed transmission rates for the five infected genotypes were 0.5 to $1.5 \%$; two of these genotypes (20SAWSN88 and 21SAWSN85) also had been found infected in the initial test. In experiment 2, WSMV was detected in grouped samples belonging to 3 of 18 additional genotypes. RT-PCR results confirmed the presence of WSMV in the grouped samples of these three genotypes and its absence in three grouped samples that were negative by ELISA (Fig. 1). The overall seed transmission rate here was $0.2 \%$, whereas the transmission rates for the three infected genotypes were 0.9 to $1.1 \%$. Sequence analysis of the 493-bp RT-
PCR products from isolates SP-2 (accession no. AY85847), SP-3 (AY85848), and SP-4 (AY85849) obtained from the three positive grouped samples showed that one was identical to SP-1 and the other two differed from it by only one nucleotide. SP-2 and SP-3 shared 99.83\% identity with the Bordertown isolate, whereas SP-4 had $100 \%$ identity. An additional nucleotide difference at the $5^{\prime}$ end of these sequences came from the SB104 primer.

\section{DISCUSSION}

We have shown for the first time that WSMV is seed transmissible in wheat. Confirmation of seedling infection came from the characteristic WSMV symptoms in wheat, ELISA with WSMV-specific antibodies, RT-PCR with WSMV-specific primers, and cDNA sequence comparisons with published WSMV sequences. In our two seed transmission experiments, all wheat seed was surface sterilized and germinated in such a way that any possibility of contact with mite vectors was eliminated. Moreover, because the virus was detected in shoot tips taken from seedlings as young as 6 days old, vector transmission would not have had time to induce detectable systemic infections in the brief interval between germination and testing. In these two experiments, seedborne infection with WSMV was identified in eight different wheat genotypes. In the initial tests on seedlings growing in the quarantine glasshouse, a further three genotypes were identified with it. Although stringent hygiene conditions to exclude mites were absent, the virus was not detected in any other susceptible host plant growing within this glasshouse or in its vicinity, providing a level of surety that the infection originated from seed. These studies found 0.2 to $0.5 \%$ seed transmission across the wheat breeding collection tested, with levels up to $1.5 \%$ in individual genotypes. However, because some of the seed in the infected seed samples from individual genotypes is likely to have come from healthy plants, the inherent transmission rate in seed only from infected plants is probably higher (9).

Table 1. Seed transmission of Wheat streak mosaic virus (WSMV) detected by enzyme-linked immunosorbent assay in eight genotypes from an International Maize and Wheat Improvement Center (CIMMYT) wheat-breeding collection propagated in Queensland, Australia

\begin{tabular}{lccc}
\hline CIMMYT wheat genotype & $\begin{array}{c}\text { Number of } \\
\text { seedlings/sample }\end{array}$ & $\begin{array}{c}\text { Positive for } \\
\text { WSMV }\end{array}$ & $\begin{array}{c}\text { Seed transmission } \\
(\%)\end{array}$ \\
\hline Seed transmission experiment 1 & 2,900 & & \\
All 25 genotypes & 180 & $6 / 290$ & 0.2 \\
20SAWSN96 & 150 & $1 / 18$ & 0.5 \\
20SAWSN88 & 130 & $2 / 15$ & 1.4 \\
21SAWSN64 & 100 & $1 / 13$ & 0.8 \\
21SAWSN85 & 70 & $1 / 10$ & 1 \\
21SAWSN151 & 1,800 & $1 / 7$ & \\
Seed transmission experiment 2 & 100 & $3 / 180$ & 0.2 \\
All 18 genotypes & 90 & $1 / 10$ & 1 \\
20SAWSN68 & 110 & $1 / 9$ & 1.1 \\
21SAWSN76 & $1 / 11$ & 0.9 \\
21SAWSN90 & & & \\
\hline
\end{tabular}

a Number of grouped samples positive/total number of grouped samples tested. 
Because of state quarantine regulations over destruction of WSMV-infected plants, we were unable to collect seed from such plants to determine the inherent transmission efficiency.

Epidemics of WSMV in wheat currently are attributed to introduction of the virus into crops by viruliferous mites arriving from external virus reservoirs consisting of WSMV-infected volunteer cereals and wild grasses. Such introductions start epidemics mainly at crop margins. Spread from the crop perimeter inward then causes more widespread infection $(2,5)$. Both virus and vector are assumed to depend entirely on a "green bridge" of living hosts for their survival outside the wheat growing season. Although this is still true for the mite vector, it is no longer an adequate explanation for WSMV. This is because incoming nonviruliferous vector mites can land on seedinfected plants scattered throughout the crop, feed, and propagate. Their progeny then can acquire the virus as nymphs (5) and spread it as viruliferous adults to nearby plants, causing an epidemic throughout the entire crop. Such widespread infection is more likely to cause damaging yield losses than spread from external sources, especially in large wheat fields with small perimeter-to-area ratios.

The demonstration that WSMV is seedborne in wheat has important implications for spread of the virus via international and local exchange of genetic materials. This is especially important when the recipient of seed is located in a region or country where the virus is not known to occur, such as in the state of Western Australia, which is isolated from the rest of the con-

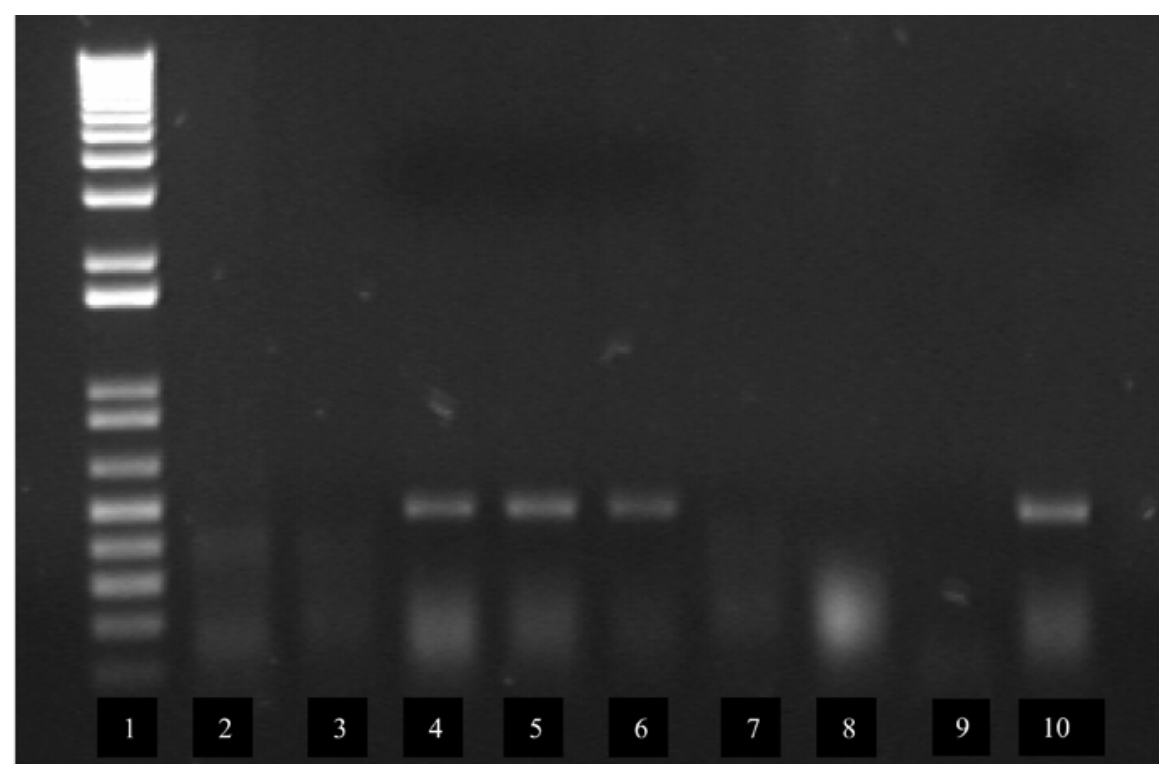

Fig. 1. Seed transmission of Wheat streak mosaic virus (WSMV) detected by reverse-transcription polymerase chain reaction tests using primers SB104 and SB105 in three genotypes from an International Maize and Wheat Improvement Center (CIMMYT) wheat-breeding collection. Lane 1, 100-bp marker; lanes 2, 3, and 7, enzyme-linked immunosorbent assay (ELISA)-negative grouped wheat seedling samples; lanes 4, 5, and 6, ELISA-positive grouped wheat seedling samples; lane 8, healthy wheat tissue; lane 9, no RNA control; lane 10, wheat tissue infected with WSMV 'Canberra' isolate. The primers amplified a 493-bp WSMV product from wheat. able procedure would be to germinate the seedlings in moist paper towels and test the shoots by ELISA or RT-PCR before discarding the infected seedlings and transplanting the remainder for seed production in an environment as free as possible from mite vectors. In regions where WSMV is endemic, testing representative samples taken from commercial seed to identify and exclude contaminated stocks would diminish the risk of an outbreak. For this, RT-PCR should be sensitive enough to test large bulked seed samples directly (14), thereby eliminating the need to grow seedlings.

\section{ACKNOWLEDGMENTS}

We thank T. N. Smith, C. P. Wang, and F. Brigg for technical support.

\section{LITERATURE CITED}

1. Altschul, S. F., Gish, W., Miller, W., Myers, E. W., and Lipman, D. J. 1990. Basic local alignment search tool. J. Mol. Biol. 215:403-410.

2. Christian, M. L., and Willis, W. G., 1993. Survival of wheat streak mosaic virus in grass hosts in Kansas from wheat harvest to fall wheat emergence. Plant Dis. 77:239-242.

3. Ellis, M. H., Rebetzke, G. J., Kelman, W. M., Moor, C. S., and Hyles, J. E. 2004. Detection of Wheat streak mosaic virus in four pasture grass species in Australia. Plant Pathol. 53:239.

4. Ellis, M. H., Rebetzke, G. J., Mago, R., and Chu, P. 2003. First report of Wheat streak mosaic virus in Australia. Australas. Plant Pathol. 32:551-553.

5. French, R., and Stenger, D. C. 2002. Wheat streak mosaic virus. AAB Descriptions of Plant Viruses, No. 293.

6. French, R., and Stenger, D. C. 2003. Evolution of Wheat streak mosaic virus: dynamics of population growth within plants may explain limited variation. Annu. Rev. Phytopathol. 41:199-214.

7. Gibbs, A. J., and Gower, J. C. 1960 . The use of a multiple-transfer method in plant virus transmission studies - some statistical points arising from the analysis of results. Ann. Appl. Biol. 113:507-518.

8. Hill, J. H., Martinson, C. A., and Russell, W. A. 1974. Seed transmission of maize dwarf mosaic and wheat streak mosaic viruses in maize and responses of inbred lines. Crop Sci. 14:232-235.

9. Jones, R. A. C. 2000. Determining 'threshold' levels for seed-borne virus infection in seed stocks. Virus Res. 71:171-183.

10. Jones, R. A. C. 2004. Occurrence of virus infection in seed stocks and 3-year-old pastures of lucerne (Medicago sativa). Aust. J Agric. Res. 55:757-764

11. Jones, R. A. C., and Cowling, W. A. 1995 Resistance to seed transmission of cucumber mosaic virus in narrow-leafed lupins (Lupinus angustifolius). Aust. J. Agric. Res. 46:13391352.

12. Stenger, D. C., Seifers, D. L., and French, R., 2002. Patterns of polymorphism in Wheat streak mosaic virus: sequence space explored by a clade of closely related viral genotypes rivals that between the most divergent strains. Virology 302:58-70.

13. Thomas, J. A., and Hein, G. L. 2003. Influence of volunteer wheat plant condition on movement of the wheat curl mite, Aceria tosichella, in winter wheat. Exp. Appl. Acarol. 31:253-268.

14. Wylie, S., Wilson, C. R., Jones, R. A. C., and Jones, M. G. K. 1993. A polymerase chain reaction assay for cucumber mosaic virus in lupin seeds. Aust. J. Agric. Res. 44:41-51. 